\title{
correspondence
}

\section{USSR bars Israeli scientist}

Sir,-We wish to protest against the discriminatory practices of the Soviet Union towards Israeli scientists wishing to participate in international scientific meetings held in the USSR.

The Fourth International Meeting on Ferroelectricity (IMF-4) was held in Leningrad on 18-23 September 1977. The meeting was organised by the Academy of Sciences of the USSR under the sponsorship of the International Union of Pure and Applied Physics, the International Atomic Energy Agency, and the European Physical Society. We had both delivered papers at the Third International Meeting on Ferroelectricity in Edinburgh in 1973, and we were looking forward to participating in IMF-4. However, at every stagesoliciting information regarding the meeting, inquiring as to the status of our submitted manuscripts, attempting to obtain an entry visa to the USSR we, and several other Israeli colleagues, encountered incredible obstacles, which ultimately led to our being unable to attend the meeting. Our individual experiences were as follows: Sidney B. Lang submitted the abstract of a paper on 29 March 1977 to Professor G. Smolensky, Chairman of IMF-4 in Leningrad. Receipt of the abstract was never acknowledged, nor was information sent regarding the status of the paper. After seeking the assistance of Professors W. Cochran (University of Edinburgh) and W. J. Merz (R.C.A., Zurich), one of us (S.H.) received a letter from Professor Cochran, dated 30 June 1977 , stating that he had received a cable from Professor Smolensky that the papers of Lang and Havlin had been accepted. Because of the impossibility of an Israeli receiving a visa to the USSR without first travelling to Western Europe, and lacking any official documentation from the Organising Committee that could be used in requesting a visa from Soviet embassies in Europe, Lang was forced to withdraw his paper on 25 August 1977. On 16 September 1977, two days before the meeting opened, Lang received the 'second circular' about the meeting, mailed from Romania on 30 August. This circular bore no date, but it specified a number of deadlines between 30 April and 18 June.

Shlomo Havlin submitted the abstract of a paper on 7 February to Pro- fessor Smolensky and as in the case of Lang, heard nothing. On 8 July the Secretary General of IUPAP, in response to requests for assistance by the Israel Physical Society, cabled that Havlin's paper was included in the meeting programme, and that he need only apply to Intourist for an entry visa. On 9 August, Havlin arrived in Paris and immediately applied for a visa at the Intourist office. At every subsequent visit to the office as well as to the Soviet Embassy, he was assured that his visa would be issued "tomorrow". The seemingly sincere promise that the visa would surely be forthcoming led Havlin to remain in Paris beyond 8 September when he had planned leaving for Leningrad. On 11 September, still with no visa, Havlin realised there was no point in continuing his battle and left Paris.

Although the organisers of the Leningrad meeting had made firm promises to IUPAP, Professor Cochran, and Professor Merz, the Soviet authorities refused to issue a visa. From our experiences, it is obvious that Israeli attendance at this international meeting was prevented by the Soviet Union.

We suggest the following to our fellow physicists and to the officials of physics organisations:

- International organisations should not sponsor meetings in the USSR without firm guarantees from the Soviet government that these meetings will be open to citizens of all nations without exception. Promises from Soviet organising committees should not be accepted in lieu of official Soviet government commitments. Scientists should write to the officers of the physics organisations to which they belong, demanding that this principle be strictly adhered to.

- Scientists should refuse to attend meetings in the USSR unless they are certain that the Soviet government has, in fact, guaranteed that the meetings will be open to citizens of all nations without exception.

- Letters should be written to the Soviet organisers of IMF-4 protesting the discrimination that was practised towards Israeli scientists. The organisers were:

\section{Chairman:}

Professor G. Smolensky

A.F. Ioffe Physico-Technical Institute Academy of Sciences of the USSR Leningrad, 194021 USSR
Vice-Chairmen:

Professors L. Shuvalov and I. Zheludev Institute of Crystallography

Academy of Sciences of the USSR Moscow, 117333 USSR

We believe that the holding of meetings without firm adherence to the above principles is totally incompatible with the international character of science and scientific research.

SIDNEY B. LANG

Ben-Gurion University of the Negev, Beersheva, Israel

\section{Shlomo Havlin}

Bar-Ilan University,

Ramat-Gan, Israel

\section{Burying high-level wastes}

SIR,-The disposal of intermediate and low level radioactive wastes in salt deposits of Permian (about $220 \mathrm{Myr}$ ) age is proceeding and proposals have been made to treat high level wastes in a similar fashion. When evaluating the suitability of these formations for this purpose, the proponents stress the antiquity, aseismicity and availability and conclude that they are "extremely stable" (The Management of Radioactive Wastes, IAEA, Vienna; 1977). Most geologists, however, would consider that rocks of this type are very unstable. Widespread halokinesis is well-documented and the role of diapirism in the formation of stratigraphic traps favourable for oil and gas accumulation is particularly significant.

In rocks containing potassium the radioactive decay of ${ }^{40} \mathrm{~K}$ forms radiogenic ${ }^{40} \mathrm{Ar}$, resulting in a high relative abundance of this isotope in the atmosphere. In early experiments designed to evaluate the possibility of using this decay scheme to measure geological time the ${ }^{40} \mathrm{Ar}$ concentrations in samples of evaporite were measured. In almost all cases it was found that significant argon loss had occurred. This was attributed to the instability of these strata and their susceptibility to dissolution by fluids (such as percolating ground water) and subsequent recrystallisation which had allowed the escape of ${ }^{40} \mathrm{Ar}$. It is not usually possible to detect these effects by examination of the rocks in hand specimen or thin section. For instance, although Suess (1948), consulted "specialists for salt mines" his analyses demonstrated that 